\title{
Genes involucrados en la biogénesis de fimbrias afectan la formación de biopelículas por parte de Klebsiella pneumoniae
}

\author{
Ana Victoria Suescún, Juan Rodrigo Cubillos, María Mercedes Zambrano \\ Grupo de Genética Molecular, Corporación CorpoGen, Bogotá, DC, Colombia
}

Introducción. Klebsiella pneumoniae es un patógeno oportunista comúnmente asociado con infecciones hospitalarias. La persistencia y patogénesis de este microorganismo pueden estar asociadas con su capacidad para formar biopelículas. Entre los factores implicados en la formación de biopelículas en diversos microorganismos están las fimbrias o pili. K. pneumoniae expresa tanto fimbria tipo 1 como fimbria tipo 3, estructuras proteicas importantes en la mediación de la adhesión a células epiteliales y la virulencia.

Objetivo. Identificar genes importantes en la formación de biopelículas de K. pneumoniae.

Materiales y métodos. K. pneumoniae MZ2098 se mutagenizó con el transposón miniTn10Km y subsecuentemente se tamizó para deficiencias en la formación de biopelículas en placas de 96 pozos usando medio BHI-MOPS. Los mutantes seleccionados se analizaron bajo diversas condiciones variando los medios de cultivo y las superficies utilizadas. Los genes interrumpidos por el transposón se identificaron mediante reacción en cadena de la polimerasa arbitraria y secuenciación.

Resultados. De un banco de 9.300 inserciones en $K$. pneumoniae se obtuvieron 37 mutantes deficientes en su capacidad para formar biopelículas. Se identificaron tres mutantes con inserciones en genes para fimbria con fenotipos notables por su diferencia en cuanto a la capacidad para adherirse a superficies in vitro.

Conclusión. Los resultados indicaron que las fimbrias tipo 1 y 3 , ésta última ya implicada en este fenómeno en K. pneumoniae, son factores importantes para la adhesión y la formación de agregados multicelulares.

Palabras clave: Klebsiella pneumoniae, infecciones oportunistas, biopelículas, fimbrias bacterianas, adherencia bacteriana, genética microbiana.

\section{Genes involved in fimbrial biogenesis affect biofilm formation in Klebsiella pneumoniae}

Introduction. Klebsiella pneumoniae is an opportunistic pathogen commonly associated with nosocomial infections. The persistence and pathogenesis of this microorganism is associated with its capacity to form biofilms. Pili or fimbriae are among the factors implicated in biofilm formation in diverse microorganisms. Klebsiella pneumoniae expresses both type 1 and type 3 fimbriae-proteinacious structures that mediate adhesion to epithelial cells and are important for virulence.

Objective. To identify genes involved in biofilm formation in $K$. pneumoniae.

Materials and methods. Klebsiella pneumoniae MZ2098 was subjected to mutagenesis with the miniTn10Km transposon and screened for defects in ability to form biofilms. The bacteria were curltured in 96-well plates using BHI-MOPS medium. Selected mutants were analyzed under diverse conditions by varying culture conditions and growth surfaces. Genes interrupted by the transposon were identified by arbitrary polymerase chain reaction and sequencing.

Results. Thirty-seven mutants deficient in biofilm formation were obtained by screening 9,300 transposon-insertion mutants in K. pneumoniae. Three of these mutants had insertions in genes that affected fimbrial formation, and their phenotypes showed severe defects in the capacity to adhere to surfaces in vitro.

Conclusion. Type 1 and type 3 fimbriae are important factors for adhesion and formation of multicellular aggregates of K. pneumoniae.

Key words: Klebsiella pneumoniae, opportunistic infections, biofilms, bacterial fimbriae, bacterial adhesion, microbial genetics. 
En el grupo de las enterobacterias existen muchas especies patógenas oportunistas de gran importancia clínica por estar directamente relacionadas con infecciones hospitalarias (1). Klebsiella spp. es miembro de este grupo y es responsable del $8 \%$ de todas las infecciones adquiridas en hospitales en el mundo occidental (2). Una de las especies más importantes de este género es Klebsiella pneumoniae, un patógeno oportunista comúnmente asociado con infecciones del tracto urinario, neumonías, septicemias e infecciones por quemaduras (3). Además, K. pneumoniae ha cobrado importancia desde hace algunos años por la aparición de cepas multirresistentes a agentes antimicrobianos y por la alta mortalidad que se reporta $(4,5)$.

Es bien conocido que las bacterias pueden formar biopelículas, las cuales son comunidades multicelulares adheridas a superficies y rodeadas por una matriz extracelular. La formación de biopelículas está asociada con la capacidad para persistir en diversos ambientes, lo que contribuye a la patogenicidad de diversas especies (6). Se ha demostrado también que las bacterias que crecen en biopelículas son más resistentes a agentes antimicrobianos que las que crecen en cultivos planctónicos debido a su estructura física y a la conformación de multicapas (7). Quizás por esto, los tratamientos de infecciones adquiridas en el hospital con los agentes antimicrobianos actuales resultan frecuentemente ineficaces (8). En el caso de K. pneumoniae, las infecciones están asociadas con el uso de catéteres en unidades de cuidados intensivos, lo cual indica que la capacidad para adherirse y formar biopelículas es importante para la patogénesis de esta bacteria.

Aunque es muy poco lo que se conoce acerca de los mecanismos empleados por Klebsiella para adherirse a superficies y formar agregados celulares, estudios realizados con otros microorganismos han revelado que las fimbrias 0

\footnotetext{
Correspondencia:

María Mercedes Zambrano, Corporación Corpogen, Carrera 5 No. 66A-34, Bogotá, DC. Tel: 348-4610, fax: 348-4607 mechas@telesat.com.co

Recibido: 30/06/06; aceptado: 08/10/06
}

pili son importantes para la formación de biopelículas por Salmonella Enteritidis (9), Pseudomonas aeruginosa (10), Staphylococcus epidermidis (11) y Escherichia coli (12). Estas estructuras proteicas reconocen un amplio rango de blancos moleculares, permitiéndole a la bacteria interactuar con diversas superficies y unirse a tejidos específicos en el hospedero (13). $K$. pneumoniae expresa un gran número de factores de adhesión, entre los cuales predominan la fimbria tipo 1 y la fimbria tipo 3 (14). La fimbria tipo 1 se encuentra en toda la familia de las enterobacterias y es una estructura delgada, rígida y adhesiva, gracias a la adhesina FimH. En estudios clínicos se ha descrito la fimbria tipo 1 como la estructura que promueve la adhesión bacteriana y la invasión a células epiteliales, factores que están implicados en la virulencia bacteriana (2). En Klebsiella, sin embargo, no se ha establecido aún su papel en la interacción con superficies abióticas. Por su parte, la fimbria tipo 3 de Klebsiella guarda alta similitud genética con su ampliamente estudiado homólogo en E. coli. Esta fimbria interviene en el reconocimiento de proteínas con residuos de manosa que se encuentran en la superficie de tejidos del hospedero, como lo es la superficie del tracto urinario $(14,15)$. Esta fimbria se expresa tanto en cepas ambientales como en cepas clínicas, es codificada por seis genes, que generalmente se encuentran en bloque, y está compuesta principalmente por la subunidad proteica MrkA. MrkA se encuentra unida a la adhesina MrkD, que media la unión a las superficies de las células epiteliales, así como a superficies abióticas (8).

El presente trabajo tuvo como objetivo principal identificar genes de K. pneumoniae involucrados en la capacidad para adherirse y formar biopelículas sobre diferentes superficies abióticas. Esto se llevó a cabo mediante mutagénesis por transposición, tamizaje de la colección e identificación de los genes alterados en mutantes incapaces de formar biopelículas. El estudio y comprensión de los mecanismos genéticos implicados en la formación de estos agregados celulares podría conducir a nuevas estrategias futuras para el control de infecciones por este patógeno oportunista. 


\section{Materiales y métodos}

\section{Cepas, medios de cultivo y condiciones de crecimiento}

La cepa clínica K. pneumoniae MZ2098 (Microbia, Inc.) se usó para los ensayos de este trabajo. La mutagénesis por transposición se realizó por conjugación, utilizando como cepa donadora a $E$. coli B2155 (pir dap), que porta el plásmido conjugativo pBSL180::miniTn10Km (16), y como cepa aceptora a K. pneumoniae MZ2098. El banco de inserciones en K. pneumoniae MZ2098 fue seleccionado en medio Luria Bertani (LB) con agar (17) suplementado con canamicina $(\mathrm{Km}, 50 \mathrm{ug} / \mathrm{ml})$ o con $3 \mathrm{mM}$ de ácido diaminopimélico (Sigma, St. Louis, MO) en caso de requerirse. Otros medios utilizados fueron medio mínimo M63 con glucosa (M63-glu) (18), agar y caldo infusión cerebrocorazón (BHI, Difco-BD, Franklin Lakes, NJ), suplementado con MOPS 2mM (Sigma, St. Louis, MO) y caldo tripticasa soya (TSB, Difco-BD, Franklin Lakes, NJ). Todos los cultivos se incubaron a $37^{\circ} \mathrm{C}$ durante 18 a 24 horas. Las cinéticas de crecimiento se hicieron a partir de cultivos de 18 horas en BHI-MOPS ajustados a una densidad óptica (DO) a 600nm de 0,05 en $25 \mathrm{ml}$ de medio fresco, e incubados 24 horas a $37^{\circ} \mathrm{C}$ en agitación (150 rpm). El crecimiento en M63-glu se hizo a partir de una dilución 1/100 en medio fresco e incubando cada mutante durante 18 horas a $37^{\circ} \mathrm{C}$. Las absorbancias fueron medidas cada hora a $600 \mathrm{~nm}$ en un espectrofotómetro Beckman DU®530 (Beckman Inc., Fullerton, CA).

\section{Mutagénesis}

La librería de mutantes con miniTn10Km se construyó por conjugación siguiendo la metodología descrita anteriormente (19). Partiendo de cultivos de 18 horas de la cepa donante $(E$. coli B2155) y la cepa recipiente (K. pneumoniae MZ2098) en medio BHI-MOPS, se hizo una dilución 1/100 en medio fresco y se incubó hasta alcanzar una DO a $600 \mathrm{~nm}$ de 0,6 a 0,8 . Posteriormente se mezclaron las dos cepas en relación 3:1 en tubos de microcentrífuga de $1,5 \mathrm{ml}$, la mezcla se concentró por centrifugación (10.000 $x \mathrm{~g} / 1 \mathrm{~min}$ ), se resuspendió en $100 \mathrm{ul}$ de caldo LB que luego se depositó como una gota uniforme sobre LB agar y la caja se incubó a $37^{\circ} \mathrm{C}$ durante
2 horas. Se raspó luego el crecimiento de la gota, se resuspendió en $1 \mathrm{ml}$ de caldo LB y se sembraron 100ul en medio selectivo (LB Km) para eliminar tanto las células de $E$. coli donantes, puesto que requieren de ácido diaminopimélico para crecer, como las células de K. pneumoniae que no recibieron el marcador de resistencia a $\mathrm{Km}$ presente en el transposón. Las colonias exconjugantes crecidas después de incubación a $37^{\circ} \mathrm{C}$ por 24 horas se inocularon con palillos estériles en placas de microtitulado de 96 pozos en 150 ul de medio BHI MOPS (con Km y $15 \%$ glicerol) y se congelaron a $-20^{\circ} \mathrm{C}$ para usar en ensayos posteriores.

\section{Ensayos de formación de biopelículas}

Se estandarizaron las condiciones óptimas para la formación de biopelículas por parte de la cepa K. pneumoniae MZ2098 probando diferentes medios de cultivo (LB, BHI-MOPS y TSB), diferentes tiempos de incubación a $37^{\circ} \mathrm{C}$ y diferentes sustratos: cajas de 96 pozos de poliestireno (MICROTESTTM96, BD-Falcon, San Jose, CA) y de polivinil cloridio (PVC, BD Falcon, San Jose, CA), tubos de polipropileno de $5 \mathrm{ml}$ (BD Falcon, San Jose, CA) y tubos de ensayo de vidrio (borosilicato) de $13 \times 100 \mathrm{~mm}$ (VWR, West Chester, PA). El tamizaje se hizo en placas de poliestireno de 96 pozos (MICROTEST TM96, BDFalcon, San Jose, CA) en medio BHI-MOPS por 18 horas. La formación de biopelículas en tubos de ensayo (vidrio y plástico) se hizo en $1 \mathrm{ml}$ de medio e incubando con agitación (150 rpm) a 37 ${ }^{\circ} \mathrm{C}$ por 18 horas; en placas de polivinil cloridio se utilizaron 150 ul de medio y el ensayo se hizo de igual manera que en el de las cajas de poliestireno. En todos los casos, el crecimiento se midió tomando la absorbancia a $595 \mathrm{~nm}$ en un lector de placas GENios (TECAN, Suiza) y se evaluó la formación de biopelícula tras descartar las células no adheridas (planctónicas), lavar los pozos con agua y teñir las células adheridas con 200 ul de cristal violeta al $1 \%$ siguiendo la metodología previamente descrita (20). Para la curva de formación de biopelícula se midió la absorbancia del cristal violeta solubilizado a las 4, 8, 24, 30 y 48 horas en el lector de placas GENios (TECAN, Suiza). Los datos obtenidos fueron el promedio de mínimo tres lecturas independientes. 


\section{Análisis fenotípicos}

Los ensayos de mucosidad se hicieron inoculando las cepas en medio LB e incubando a $37^{\circ} \mathrm{C}$ durante 18 horas. Posteriormente, se centrifugó cada cultivo a $2.000 \mathrm{rpm}$ por 5 minutos y se midió la densidad óptica del sobrenadante a $600 \mathrm{~nm}$ (21). Esta prueba se realizó tres veces y los resultados fueron consistentes. Se evaluó la morfología de colonia a partir de un cultivo de 18 horas en LB sin sal, el cual se diluyó $1 / 100$ en medio fresco y se sembraron 10 ul sobre LB agar $1,5 \%$ sin sal, con rojo congo $(40 \mathrm{ug} / \mathrm{ml})$ y azul de Coomassie (20ug/ml), y en LB agar $1,5 \%$ con calcofluor $(0,2 \mathrm{mg} / \mathrm{ml})$. Después de una incubación a $28^{\circ} \mathrm{C}$ durante 24 horas se evaluó la morfología de cada mutante.

\section{Reacción en cadena de la polimerasa abitraria}

La primera ronda de la reacción en cadena de la polimerasa (PCR) arbitraria se hizo de acuerdo con protocolos establecidos (19) con iniciadores específicos para el miniTn10Km (P12 = 5'CAGCGCATCGCCTTCTATCGC-3' O P20 = 5'CCGCGGTGGAGCTCC-3') y otros diseñados para anillar azarosamente en el cromosoma de la bacteria (ARB1 = 5' -GGCCACGCGTCGACTAG TACNNNNNNNNNNGATAT-3; $A$ RB6 = 5'GGCCACGCGTCGACTAGTACNNNNNNNNNNACGCC-

$\left.3^{\prime}\right)$. Esta amplificación se hizo usando como templado 2,5 ul del sobrenadante de células hervidas durante $10 \mathrm{~min}$ a $90^{\circ} \mathrm{C}$ en un volumen de 25 ul que contenía $200 u M$ de cada nucleótido, $0,3 \mathrm{uM}$ de cada iniciador, $2 \mathrm{mM}$ de $\mathrm{MgCl}_{2}$ y 0,2 $\mathrm{U} / \mathrm{ul}$ de Tucan Taq polimerasa (CorpoGen, CO) con el siguiente programa: $95^{\circ} \mathrm{C}$ por 5 minutos, seguido por 5 ciclos de 30 segundos a $94^{\circ} \mathrm{C}, 30$ segundos a $30^{\circ} \mathrm{C}$ y 1 minuto a $72^{\circ} \mathrm{C} ; 30$ ciclos de 30 segundos a $94^{\circ} \mathrm{C}, 30$ segundos a $45^{\circ} \mathrm{C}$ y 1 minuto a $72^{\circ} \mathrm{C}$, y una extensión final de $72^{\circ} \mathrm{C}$ por 5 minutos. A partir de estos amplificados se hizo una segunda ronda de amplificación con iniciadores internos a los anteriores, P11= 5'-CTTGACGAGTTCTGAGC GGG-3' O P2 = 5'-ATGACAAGATGTGTATCC ACC-3' y ARB2 = 5'-GGCCACGCGTCGACTAG TAC-3'. La reacción se llevó a cabo en un volumen de 50 ul que contenía 200 uM de cada nucleótido, $0,3 \mathrm{uM}$ de cada iniciador, $2 \mathrm{mM}$ de $\mathrm{MgCl}_{2}, 0,2 \mathrm{U} /$ ul de Tucan Taq polimerasa (CorpoGen, CO) y 5 ul producto de la primera ronda. El perfil de temperatura utilizado fue de $95^{\circ} \mathrm{C}$ por 5 minutos, seguido por 30 ciclos de 30 segundos a $94^{\circ} \mathrm{C}, 30$ segundos a $50^{\circ} \mathrm{C}$ y 1 minuto a $72^{\circ} \mathrm{C}$, con una extensión final de $72^{\circ} \mathrm{C}$ por 5 minutos. Los productos amplificados fueron purificados con el Qiaquick PCR purification kit (Qiagen, CA) y secuenciados en Macrogen (Corea). Los oligonucléotidos fueron de IDT (Coralville, IA).

\section{Análisis bioinformático}

Se hizo un análisis bioinformático de las regiones secuenciadas utilizando la base de datos PEDANT (22) y el genoma completo de $K$. pneumoniae MGH 78578 (http://genomeold. wustl.edu/ projects/bacterial/kpneumoniae/) por medio de los programas Artemis (23), ORF Finder (NCBI) y GenMark (24) y los algoritmos blastn, blastx y blastp (25).

\section{Resultados}

\section{Aislamiento de mutantes deficientes en la formación de biopelículas}

Se creció un mutante por pozo y luego de eliminar las células planctónicas, las células adheridas a cada pozo se tinieron con cristal violeta (figura 1). Aquellos mutantes que demostraron una reducción en la formación de biopelícula, de acuerdo con la tinción con cristal violeta, se probaron múltiples veces usando la misma estrategia. De este tamizaje inicial se obtuvieron 37 mutantes (M1-M37) deficientes en la producción de biopelículas, los cuales mostraron entre un 12 y $96 \%$ de la capacidad para formar biopelículas con respecto a la cepa parental.

Como siguiente paso se procedió a identificar el sitio de inserción del transposón en cada uno de los mutantes de interés. Mediante PCR arbitrarias se secuenciaron las regiones cromosomales adyacentes al transposón y a partir de las secuencias obtenidas se realizó un análisis parcial de la mayoría de las secuencias interrumpidas en las cepas deficientes en la formación de biopelículas. En particular, los mutantes M22, M27 y M29 parecían tener deficiencias en la formación de fimbrias, componentes importantes de la superficie celular de $K$. pneumoniae. Adicionalmente, al hacer un análisis de Southern 


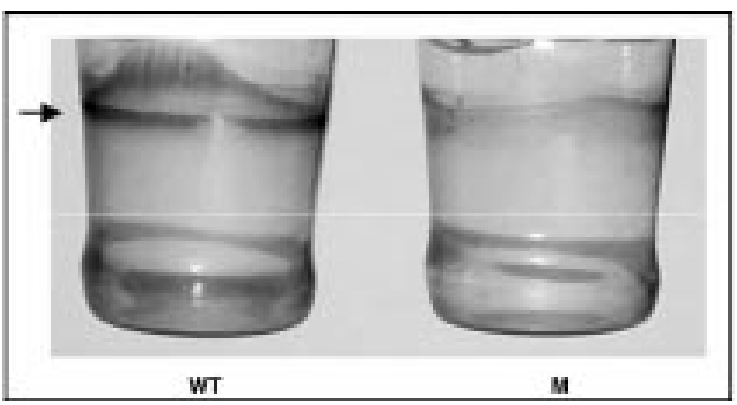

Figura 1. Formación de biopelícula en pozos de poliestireno. La presencia de un anillo en el pozo indica la presencia de biopelícula (indicado con una flecha) en la cepa parental (WT) y la ausencia en un mutante deficiente en este fenotipo (M) después de tinción con cristal violeta.

blot utilizando una sonda marcada con biotina y dirigida contra el transposón, se pudo verificar que estos mutantes contenían una única inserción del transposón en el genoma. Debido a la importancia que pueden tener estas estructuras protéicas de la superficie celular se decidió, por consiguiente, profundizar un poco más en el análisis de estos mutantes.

\section{Análisis de mutantes que afectan fimbrias}

Como se puede observar en la figura $2 \mathrm{~A}$, el mutante M22 afecta un gen que tiene un $85 \%$ de similitud con el gen fimE de E. coli. Este gen es una recombinasa involucrada en la variación de fase y la regulación del gen fimA, la subunidad principal de la fimbria tipo 1. Los mutantes M27 y
M29, por su parte, afectan la expresión de la fimbria tipo 3 (figura 2B). En el caso de M27, la inserción se encuentra antes del primer gen del operón que codifica para los genes de la fimbria tipo $3(m r k A)$, y la inserción en M29 interrumpe directamente el gen $m r k C$ que codifica para una proteína involucrada en el ensamble y biogénesis de la fimbria en la membrana externa.

Estos mutantes se analizaron luego bajo diversas condiciones de cultivo. En primer lugar se hicieron curvas de crecimiento tanto en BHI-MOPS, el mismo medio utilizado para la identificación de los mutantes, como en medio mínimo de sales, M63-glu, para saber si estas mutaciones alteraban alguna función esencial. Como era de esperarse, los mutantes no demostraron deficiencias en su curva de crecimiento en medio mínimo (cuadro 1). Al hacer curvas de crecimiento en BHI-MOPS se observó que crecieron con cinéticas muy similares a las de la cepa parental (figura 3).

\section{Análisis de biopelículas bajo diferentes condiciones}

Como se puede observar en el cuadro 1, los fenotipos de los diferentes mutantes analizados variaron entre sí. Mientras que el mutante M22, que afecta la fimbria tipo 1, presenta un fenotipo disminuido de formación de biopelícula en $\mathrm{BHI}$ MOPS, los mutantes M27 y M29, que afectan la fimbria tipo 3, son completamente deficientes en formación de biopelícula. Por otro lado, el mutante

A

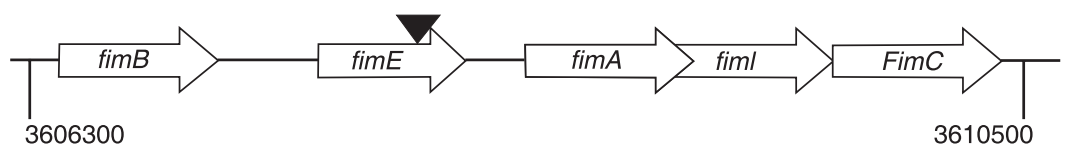

B

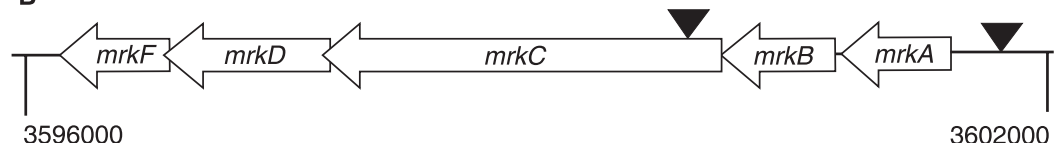

Figura 2. Posición de las inserciones en los mutantes deficientes en formación de fimbria. Se muestran las regiones afectadas en la formación de fimbria tipo 1 (A) y fimbria tipo 3 (B). Los números bajo cada línea indican las coordenadas de acuerdo con el genoma completo de K. pneumoniae MGH 78578; las flechas horizontales indican la dirección de la transcripción de cada gen, y las flechas negras verticales indican la posición de cada una de las inserciones. Sólo se muestra la primera parte de la región para los genes de la fimbria tipo 1. 


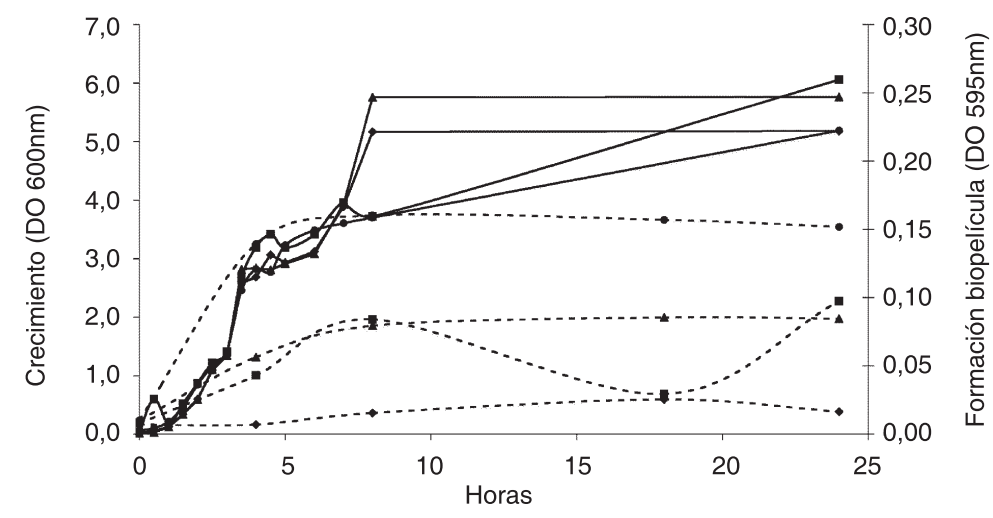

Crecimiento — Biopelículas ---- Cepa silvestre $\quad$ M22 $\square$ M27 $\mathbf{\Delta}$ M29

Figura 3. Crecimiento y formación de biopelículas. Se siguió el crecimiento por densidad óptica (DO) a 600 nm (líneas negras) y se analizó la capacidad para formar biopelículas mediante tinción y cuantificación con cristal violeta a $595 \mathrm{~nm}$ (líneas punteadas) para la cepa silvestre (círculos) y los mutantes M22 (cuadros), M27 (triángulos) y M29 (diamantes).

M22 forma una biopelícula bajo algunas condiciones analizadas, mientras que las cepas M27 y M29 no lo hacen en ninguno de los medios utilizados. Al hacer una curva de formación de biopelícula en BHI-MOPS sobre placas de poliestireno se observó una marcada reducción en la capacidad de adhesión de los tres mutantes con respecto a la cepa silvestre. Aunque los tres mutantes mostraron un fenotipo disminuido, el mutante M29 mostró mayor deficiencia en este ensayo durante las primeras 24 horas de incubación (figura 3).

Teniendo en cuenta estos datos, se evaluó la capacidad de los mutantes para crecer y formar biopelículas sobre diferentes tipos de superficies: PVC, polipropileno, poliestireno y vidrio (cuadro 1). En general no se observaron diferencias significativas con respecto al fenotipo detectado originalmente en las placas de microtitulación de poliestireno cuando se utilizaron materiales como PVC y polipropileno. Se observó también que el fenotipo de deficiencia en formación de biopelícula en placa se mantuvo cuando se hizo la evaluación en tubos de vidrio. Al hacer estos análisis fue evidente, una vez más, que había diferencias entre los dos grupos de mutantes, puesto que el M22 mostró en general un fenotipo menos penetrante que los mutantes en la fimbria tipo 3 , M27 y M29.

\section{Análisis de la producción de exopolisacáridos}

En este caso, las cepas también mostraron diferencia con respecto a la cepa parental (cuadro 1). Es interesante anotar que las diferentes inserciones afectan la mucosidad de las células de manera diferente, aun cuando todas alteran estructuras proteicas de superficie como son las fimbrias.

Adicionalmente, se evaluó el fenotipo de las colonias sobre medios que se han utilizado para analizar diferencias en componentes de la matriz extracelular en otros microorganismos, particularmente en Salmonella (26). En medio LB con rojo Congo y azul de Coomassie es posible evaluar la presencia de celulosa o fimbria, ya que los fenotipos de las células varían dependiendo de la presencia de estos componentes (26). El crecimiento sobre el medio LB con calcofluor sirve para detectar la presencia de celulosa en la matriz extracelular, ya que estas células fluorescen bajo luz ultravioleta. Como se resume en el cuadro 1 , los mutantes en genes implicados en la formación de fimbrias, tanto la fimbria tipo 1 como la fimbria tipo 3, presentaron fenotipos de colonia muy similares a la cepa silvestre parental en el medio con rojo Congo. La cepa deficiente en producción de fimbria tipo 1 (M22) presentó diferencias más marcadas con respecto a la cepa parental que las cepas deficientes en fimbria tipo 3 (M27 y 
Cuadro 1. Características de los diferentes mutantes y la cepa silvestre (WT).

\begin{tabular}{|c|c|c|c|c|c|}
\hline \multirow[b]{2}{*}{ Mutante } & \multirow[b]{2}{*}{ Crecimiento M63glu } & \multirow{2}{*}{$\begin{array}{c}\text { Biopelícula } \\
\text { Medios y soportes }^{*}\end{array}$} & \multicolumn{3}{|c|}{ Fenotipo } \\
\hline & & & Mucoide $^{\star *}$ & Rojo Congo & Calcofluor \\
\hline 22 & + & $+/-$ & 3 & Rosada,más rugosa & - \\
\hline 27 & + & - & 1 & rosada & - \\
\hline 29 & + & - & 2 & rosada & - \\
\hline WT & + & + & 2 & rosada & - \\
\hline
\end{tabular}

$+\mathrm{y}-$ indica presencia y ausencia del fenotipo.

*Medios: BHI, MOPS, LB, TSB; Soportes: PVC, polipropileno, polietileno, vidrio (18 horas)

** 1 indica menor mucosidad y 3 mayor mucosidad.

M29), corroborando que existen diferencias a nivel de la matriz extracelular. Estas diferencias, aunque leves, no se extienden a la producción de celulosa, puesto que al crecer en medio con calcofluor, el fenotipo de las mutantes fue idéntico al de la cepa silvestre, pues ninguna de las cepas mostró fluorescencia.

\section{Discusión}

En este estudio se obtuvo un banco de mutantes por transposición en K. pneumoniae, el cual fue luego tamizado para deficiencias en la formación de biopelículas en placas de microtitulación. De esta manera, fue posible identificar rápidamente mutantes con alteraciones en su capacidad de adherirse y formar biopelículas en placas de poliestireno, entre los cuales se encontraron mutantes con defectos en la producción de fimbrias. Uno de los mutantes identificados tenía una inserción que afectaba la producción de fimbria tipo 1, mientras que otros dos afectaban la producción de fimbria tipo 3 . Estos mutantes, a pesar de haber sido identificados por su deficiencia en formación de biopelícula en placas de poliestireno, también presentaron deficiencias en las otras superficies analizadas en este trabajo (polipropileno, PVC y vidrio). Esto indica que las condiciones de tamizaje lograron identificar mutantes que mantenían su fenotipo bajo diversas condiciones ambientales, lo cual también fue evidente al analizar estas cepas en diferentes medios de cultivo. Por último, los mutantes no mostraron diferencias en las cinéticas de crecimiento con respecto a la cepa parental cuando se incubaron en medio definido (M63-glu) ni en medio enriquecido (BHI-MOPS). Estos resultados indican, por consiguiente, que la falla en formación de biopelículas se debe a la interrupción de un componente esencial para este proceso y no a diferencias en las tasas de crecimiento de los mutantes.

Análisis previos de la capacidad para formar biopelículas por parte de K. pneumoniae han revelado un número limitado de componentes importantes para este proceso. En contraste con un estudio anterior, en el cual se obtuvieron pocos mutantes por transposición (8), en este trabajo se identificaron 37 mutantes deficientes en producción de biopelículas. Dos de estos mutantes tenían inserciones que afectan la biogénesis de la fimbria tipo 3 , componente implicado en la capacidad de K. pneumoniae para adherirse a tejidos epiteliales y que ha sido reportado previamente como un factor importante para la formación de biopelículas in vitro $(8,14)$. Mientras que la adhesina MrkD de esta fimbria tipo 3 media unión a células epiteliales, MrkA, su principal componente estructural, es la subunidad involucrada más directamente en la adhesión a superficies abióticas (8). La identificación de dos mutantes que afectan la formación de fimbria tipo 3 en este estudio en primer lugar indica que el tamizaje utilizado fue eficiente para la identificación de factores importantes para la formación de biopelículas in vitro. Una de estas inserciones (M27) muy probablemente afecta expresión del operón ya que ocurre anterior al primer gen $m r k A$. La segunda inserción (M29) ocurre corriente abajo en el gen $m r k C$ que se requiere para el ensamblaje correcto de esta fimbria. Estos dos mutantes son completamente deficientes en formación de biopelículas sobre las superficies analizadas aquí, muy probablemente 
debido a que ninguna de estas dos cepas produce fimbria tipo 3. Esto indica, una vez más, que este componente de la bacteria es muy importante en los pasos de adhesión y formación de agregados celulares sobre diferentes tipos de superficies abióticas.

Además de la identificación de mutantes en fimbria tipo 3, en este trabajo también se identificó un tercer mutante que afecta genes necesarios para la expresión de la fimbria tipo 1. Esta fimbria en $E$. coli está sujeta a regulación por variación de fase, en la que el promotor anterior al gen fimA, que codifica para la subunidad estructural, se invierte gracias a la acción de dos recombinasas codificadas por los genes fimB y fimE (27). En este caso, la inserción del miniTn10Km ocurrió en el gen fimE, muy probablemente afectando la inversión y, por consiguiente, la expresión a partir del promotor anterior a fimA. Estos resultados concuerdan con reportes que indican que la fimbria tipo 1 es importante para la formación de biopelículas en E. coli (12). Por el contrario, un estudio anterior en el que se analizaron cepas de K. pneumoniae con variaciones en la expresión de fimbria tipo 1 concluyó que este componente no jugaba un papel en la adhesión a superficies (14). Los resultados obtenidos aquí indican que la fimbria tipo 1 sí juega un papel en la capacidad de $K$. pneumoniae para adherirse a superficies abióticas, aunque la deficiencia en estos mutantes no es tan marcada como la que se observa en los mutantes para la fimbria tipo 3 . Es posible que la discrepancia en resultados se deba al tipo de análisis realizados o a diferencias entre las cepas utilizadas para los estudios. En este sentido, sería interesante analizar y cuantificar la capacidad para formar biopelículas en cepas clínicas con diferentes niveles de expresión de esta fimbria.

La identificación de mutantes en genes que afectan la formación de fimbrias en la membrana externa de la célula corroboran y amplían resultados anteriores sobre la importancia de estas estructuras en la adhesión y formación de biopelículas microbianas. En este estudio no sólo se identificaron mutantes en fimbria tipo 3 sino que además se pudo determinar que la fimbria tipo 1 también juega un papel importante en $K$. pneumoniae. La ausencia de fimbria tipo 3 resulta en un fenotipo más penetrante que el mutante que carece de fimbria tipo 1 en cuanto a deficiencia en la capacidad de formar biopelículas. Esta diferencia se observó bajo diversas condiciones de incubación y utilizando diversas superficies. Sin embargo, los fenotipos de colonia sobre medios con rojo Congo y azul de Coomassie fueron muy similares entre la cepa parental y las cepas deficientes en fimbria tipo 3, lo cual sugiere que contrario a lo que sucede en $S$. typhimurium, la ausencia de estas fimbrias no altera notablemente las características de la colonia en estos medios. Estos análisis son interesantes debido a que en otros organismos se ha reportado que las alteraciones en componentes de la superficie, como las fimbrias o el contenido de polisacáridos de la matriz extracelular, afectan no sólo el fenotipo de la colonia sobre diversos medios sino que se asocian también con cambios en su capacidad para formar agregados multicelulares y biopelículas $(26,28)$. En este caso, la ausencia de diferencias evidentes a nivel de fenotipo de colonia se puede deber a la presencia de otros factores en la superficie de Klebsiella. Además de estas dos fimbrias, se han reportado componentes adicionales que aparentemente median adherencia a células eucariotas y que pueden ser proteicos, como KPF-28, o de material tipo capsular (29). Sería interesante, por consiguiente, analizar los fenotipos de colonia y la capacidad para formar biopelículas en células que carecen de ambas fimbrias, tipo 1 y tipo 3. Aunque es posible que otras moléculas presentes en la superficie celular también puedan afectar la capacidad para formar agregados multicelulares, nuestro tamizaje no identificó determinantes adicionales de este tipo. Esto tal vez se deba a que es posible que estas mutaciones no generen un fenotipo fácilmente distinguible del fenotipo silvestre bajo las condiciones de ensayo utilizadas.

Es evidente que la formación de biopelículas microbianas involucra una serie coordinada de eventos que requiere de múltiples pasos y señales (30). En un organismo no mótil como $K$. pneumoniae, estructuras proteicas como las fimbrias evidentemente juegan un papel importante en la adhesión a diferentes sustratos. Los análisis 
de otros mutantes identificados en este trabajo están en progreso y muy seguramente podrán darnos nuevas pistas acerca de otros mecanismos empleados por esta bacteria para formar biopelículas. Un mejor conocimiento de este proceso podría ayudar a entender la capacidad que tiene $K$. pneumoniae para crecer y desarrollarse sobre superficies, lo cual contribuiría a buscar estrategias para controlar su persistencia y diseminación en el contexto clínico.

\section{Agradecimientos}

Quisiéramos agradecer la ayuda brindada por R. Kolter y todos los miembros de Corpogen.

\section{Conflicto de intereses}

Declaramos que el presente trabajo y los resultados derivados no representan ningún tipo de conflicto de intereses para los autores.

\section{Financiación}

Este trabajo fue financiado por Microbia Inc., Colciencias (Proyecto código 6570-05-14653) y por la Fundación para la Promoción de la Investigación y la Tecnología del Banco de la República.

\section{Referencias}

1. Tsay RW, Siu LK, Fung CP, Chang FY. Characteristics of bacteremia between communityacquired and nosocomial Klebsiella pneumoniae infection: risk factor for mortality and the impact of capsular serotypes as a herald for community-acquired infection. Arch Intern Med 2002;162:1021-7.

2. Schembri MA, Blom J, Krogfelt KA, Klemm P. Capsule and fimbria interaction in Klebsiella pneumoniae. Infect Immun 2005;73:4626-33.

3. Maroncle N, Balestrino D, Rich C, Forestier C. Identification of Klebsiella pneumoniae genes involved in intestinal colonization and adhesion using signaturetagged mutagenesis. Infect Immun 2002;70:4729-34.

4. Anderl JN, Franklin MJ, Stewart PS. Role of antibiotic penetration limitation in Klebsiella pneumoniae biofilm resistance to ampicillin and ciprofloxacin. Antimicrob Agents Chemother 2000;44:1818-24.

5. Bouza E, Cercenado E. Klebsiella and Enterobacter: antibiotic resistance and treatment implications. Semin Respir Infect 2002;17:215-30.

6. Mah TF, O'Toole GA. Mechanisms of biofilm resistance to antimicrobial agents. Trends Microbiol 2001;9:34-9.
7. Donlan RM, Costerton JW. Biofilms: survival mechanisms of clinically relevant microorganisms. Clin Microbiol Rev 2002;15:167-93.

8. Langstraat J, Bohse M, Clegg S. Type 3 fimbrial shaft (MrkA) of Klebsiella pneumoniae, but not the fimbrial adhesin (MrkD), facilitates biofilm formation. Infect Immun 2001;69:5805-12.

9. Austin JW, Sanders G, Kay WW, Collinson SK. Thin aggregative fimbriae enhance Salmonella enteritidis biofilm formation. FEMS Microbiol Lett 1998;162:295301.

10. O'Toole GA, Kolter R. Flagellar and twitching motility are necessary for Pseudomonas aeruginosa biofilm development. Mol Microbiol 1998;30:295-304.

11. Heilmann C, Hussain M, Peters G, Gotz F. Evidence for autolysin-mediated primary attachment of Staphylococcus epidermidis to a polystyrene surface. Mol Microbiol 1997;24:1013-24.

12. Pratt LA, Kolter R. Genetic analysis of Escherichia colibiofilm formation: roles of flagella, motility, chemotaxis and type I pili. Mol Microbiol 1998;30:285-93.

13. Klemm P, Schembri MA. Bacterial adhesins: function and structure. Int J Med Microbiol 2000;290:27-35.

14. Di Martino P, Cafferini N, Joly B, Darfeuille-Michaud A. Klebsiella pneumoniae type 3 pili facilitate adherence and biofilm formation on abiotic surfaces. Res Microbiol 2003;154:9-16.

15. Martinez JJ, Mulvey MA, Schilling JD, Pinkner JS, Hultgren SJ. Type 1 pilus-mediated bacterial invasion of bladder epithelial cells. Embo J 2000;19:2803-12.

16. Alexeyev MF, Shokolenko IN. Mini-Tn10 transposon derivatives for insertion mutagenesis and gene delivery into the chromosome of gram-negative bacteria. Gene 1995;160:59-62.

17. Sambrook J, Fritsch EF, Maniatis T. Molecular cloning: A laboratory manual. Cold Spring Harbor: Cold Spring Harbor Laboratory Press; 1989. p.1659.

18. Miller JH. A short course in bacterial genetics: a laboratory manual and handbook for Escherichia coli and related bacteria. Plainview: Cold Spring Harbor Laboratory Press; 1992. p.496.

19. Watnick PI, Kolter R. Steps in the development of a Vibrio cholerae El Tor biofilm. Mol Microbiol 1999;34:586-95.

20. O'Toole GA, Kolter R. Initiation of biofilm formation in Pseudomonas fluorescens WCS365 proceeds via multiple, convergent signalling pathways: a genetic analysis. Mol Microbiol 1998;28:449-61.

21. Lai YC, Peng HL, Chang HY. RmpA2, an activator of capsule biosynthesis in Klebsiella pneumoniae CG43, regulates K2 cps gene expression at the transcriptional level. J Bacteriol 2003;185:788-800. 
22. Frishman D, Mokrejs M, Kosykh D, Kastenmuller G, Kolesov G, Zubrzycki I, et al. The PEDANT genome database. Nucleic Acids Res 2003;31:207-11.

23. Rutherford K, Parkhill J, Crook J, Horsnell T, Rice $P$, Rajandream MA, et al. Artemis: Sequence visualization and annotation. Bioinformatics 2000;16:944-5.

24. Hagiwara H, Naitou M, Shibata T, Hanaoka F, Eki T, Murakami Y. Identification of the coding region of Saccharomyces cerevisiae chromosome VI using the computer program GenMark. DNA Res 1995;2:24753.

25. McGinnis S, Madden TL. BLAST: at the core of a powerful and diverse set of sequence analysis tools. Nucleic Acids Res 2004;32:W20-5.

26. Zogaj X, Bokranz W, Nimtz M, Romling U. Production of cellulose and curli fimbriae by members of the family
Enterobacteriaceae isolated from the human gastrointestinal tract. Infect Immun 2003;71:4151-8.

27. Joyce SA, Dorman CJ. A Rho-dependent phasevariable transcription terminator controls expression of the FimE recombinase in Escherichia coli. Mol Microbiol 2002;45:1107-17.

28. Solano C, Garcia B, Valle J, Berasain C, Ghigo JM, Gamazo C, et al. Genetic analysis of Salmonella enteritidis biofilm formation: critical role of cellulose. Mol Microbiol 2002;43:793-808.

29. Podschun R, Ullmann U. Klebsiella spp. as nosocomial pathogens: epidemiology, taxonomy, typing methods, and pathogenicity factors. Clin Microbiol Rev 1998;11:589-603.

30. O'Toole G, Kaplan HB, Kolter R. Biofilm formation as microbial development. Annu Rev Microbiol 2000; 54:49-79. 